\title{
Tracing the signature dynamics of foreign language classroom anxiety and foreign language enjoyment: A retrodictive qualitative modeling
}

\author{
Majid Elahi Shirvana* (D), Nahid Talebzadeha (D) \\ aUniversity of Bojnord, Bojnord, Iran \\ Received 27 February 2019 | Received in revised form 14 April 2019 | Accepted 2 May 2019
}

\begin{abstract}
APA Citation:
Elahi Shirvan, M., \& Talebzadeh, N. (2020). Tracing the signature dynamics of foreign language classroom anxiety and foreign language enjoyment: A retrodictive qualitative modeling. Eurasian Journal of Applied Linguistics, 6(1), 23-44.
\end{abstract}

Doi: 10.32601/ejal.710194

\begin{abstract}
With the shift from negative psychology to positive psychology in the field of applied linguistics, and in alignment with the dynamic turn in this filed, recent studies have tried to micro-map foreign language classroom anxiety (FLCA) and foreign language enjoyment (FLE) from a dynamic perspective. However, the signature dynamics of learners' FLCA, as a negative emotion, and FLE, as a positive emotion, are yet to be explored. Inspired by Dörnyei (2014), we used the innovative approach of retrodictive qualitative modeling (RQM) to explore the signature dynamics of the two variables. Having identified the learner archetypes of FLE and FLCA via focus-group interviews with a group of teachers regarding their learners' enjoyment and anxiety experiences, we conducted in-depth interviews with one prototypical student from each archetype in order to discover the trends and trajectories leading to a specific outcome or attractor state by tracking and investigating the dynamic occurrences backwards. The results provided us with new insights into the dynamic trends leading to different archetypes of FLE and FLCA as well as the adoptability of the RQM to studies on the dynamics of enjoyment and anxiety.
\end{abstract}

(C) 2020 EJAL \& the Authors. Published by Eurasian Journal of Applied Linguistics (EJAL). This is an open-access article distributed under the terms and conditions of the Creative Commons Attribution license (CC BY-NC-ND) (http://creativecommons.org/licenses/by-nc-nd/4.0/).

Keywords: foreign language classroom anxiety; foreign language enjoyment; signature dynamics; retrodictive qualitative modeling; archetype

\section{Introduction}

When speaking of the dynamic nature of human beings' systems, we come to realize that the extent of complexity is far more than the predictability in the systems' operations (Haggis, 2008) and since the behavior of a complex system is neither entirely arbitrary nor predictable (Larsen-Freeman, \& Cameron, 2008), conducting research to envelope the limited predictions regarding the interaction of various factors in the dynamic systems of self-reflective human beings sounds a demanding task (Dörnyei, MacIntyre, Henry, 2015). This issue and the inability of making assumptions concerning the predictors of the outcomes in these systems pose serious

\footnotetext{
* Corresponding author.

E-mail address: elahimajid64@gmail.com;m.elahi@ub.ac.ir http://dx.doi.org/10.32601/ejal.710194
} 
problems for researchers (Chan, Dörnyei, Henry, 2015). Thus, investigating the complexities of foreign language learners' dynamic patterns and how they develop over time requires an appropriate methodological perspective. Considering the limitations previously mentioned, to come up with the appropriate methodology for research, Dörnyei (2014) put emphasis on the self-organizing capacity of the dynamic systems. He asserted that due to this self-organizing capacity, which highlights order out of their nonlinearity and fluidity, complex systems show a few well-established patterns and behavioral outcomes which provide a meaningful outlet for exploring dynamic systems via retrodictive qualitative modeling (RQM). Following two basic human tendencies underlying their system dynamics, (Chan, Dörnyei, \& Henry, 2015; MacIntyre \& Serroul, 2015), learners of a foreign language approach situations inducing positive emotions and avoid those triggering negative ones. This study was designed based on RQM in order to focus explicitly on changes of the two most recognizable emotions in the field of psychology of foreign language learning and teaching, foreign language enjoyment (FLE) and foreign language classroom anxiety (FLCA), from a backward progression view (Byrne, 2010).

\subsection{Foreign language enjoyment and anxiety}

Anxiety has been the most studied emotion in the field of applied linguistics (e.g. Dewaele, 2007; Horwitz, 2001; Lu \& Liu, 2011; MacIntyre, 1999; MacIntyre, \& Gardner, 1991; Saito, Horwitz, \& Garza, 1999; Scovel, 1978; see Horwitz, 2010 and Gkonou, Daubney \& Dewaele, 2017 for a review of literature) which has rendered positive emotions such as enjoyment isolated. In the past few years, the focus on negative emotions has been shifted to the investigation of positive emotions, especially enjoyment (e.g. Deweale, \& MacIntyre, 2014; Dewaele, Dewaele, 2017; Dewaele, MacIntyre, Boudreau, \& Dewaele, 2016; Elahi Shirvan \& Talebzadeh; 2018 a; Krentzman, 2013; Pluskota, 2014). Since positive emotions are as important as negative emotions in foreign language learning, we are not supposed to lose gaining deep insights into them (Arnold \& Brown, 1999). However, this does not mean to overlook the importance of negative emotions as well. Deweale and MacIntyre (2014, 2016) have emphasized the importance of both positive and negative emotions referring to them as the right and left feet of a language learner.

Recent studies on both emotions in the field of foreign language learning have highlighted them as situated dynamic states rather than traits. They enter different phases of change across time and each state is the continuation of a previous state (Gregersen, MacIntyre, \& Meza, 2014, Elahi Shirvan \& Talebzadeh, 2017). Different variables influence the emerging states of these emotions in a network of interconnections (Elahi Shirvan \& Taherian, 2018; Elahi Shirvan \& Talebzadeh, 2017).

Recent research has also indicated that both FLE and FLCA are in alignment with the main features of dynamic systems. First, dynamic systems change over time (de Bot, Lowie, \& Verspoor, 2007). Dewaele and Dewaele (2017), Dewaele and Alfawzan 
(2018), Dewaele, MacIntyre, and Boudreau (2018) as well as Elahi Shirvan and Taherian (2018) have confirmed the fact that states of FLE and FLCA change across time. Furthermore, Elahi Shirvan and Talebzadeh (2018a) indicated that learners' feeling of enjoyment fluctuates over time under the influence of topics presented to them.

Second, the existing system variables are interconnected and the space state of each variable might be under the influence of the other variables in the system and vice versa (Larsen-Freeman, 2015). Dewaele and MacIntyre (2014, 2016), investigating the weight of enjoyment as a positive emotion in foreign language classrooms, reported that anxiety as a negative emotion can be experienced together with enjoyment in these classes. In addition, Dewaele, Witney, Saito and Dewaele (2017) found that, within a specific classroom context, FLE and FLCA can be associated with a variety of variables specific to the class such as the teacher and the use of foreign language in the class or some internal variables specific to learners like learners' attitudes towards the foreign language.

Third, dynamic systems are feedback sensitive (de Bot et al., 2007). That is, dynamic systems change in reaction to feedback from their environments. Elahi Shirvan and Talebzadeh (2018 a) concluded that FLE changes in response to different conversational topics. In addition, Elahi Shirvan and Talebzadeh (2017) concluded that foreign language anxiety goes under change in response to interlocutors' status and familiarity in conversations. Furthermore, Dewaele and Dewaele (2017) found that teachers, as important ecological sources of feedback within the complex system of classrooms, are strong predictors of enjoyment. That is, in response to teachers' questions, expectations, and behavior, learners might experience states of enjoyment or boredom. Moreover, Dewaele and MacIntyre (2014) reported that positive, respectful, and well-organised behaviour of teachers as well as their sympathizing laughter can contribute to learners' moments of enjoyment in the class.

Fourth, the computation of the average behavior in complex systems does not convey the behavior of the system's components (Larsen-Freeman, 2006). Due to this fact, "L2 learners do not form ergodic ensembles" (Lowie \& Verspoor, 2018, p. 1). Recent research has found no fixed nonverbal communication cue entirely indicating enjoyment (Elahi Shirvan \& Talebzadeh, 2018 b) and language anxiety (Gregersen, MacIntyre, \& Olson, 2017). For example, prompt movements of body by some learners can signal enjoyment while, used by some others, they might indicate anxiety.

Fifth, dynamic systems are context dependent (Larsen-Freeman, 2016). Dewaele and MacIntyre (2014) regarded a pivotal role for the classroom environment in learners' experiences of enjoyment and anxiety. Moreover, putting emphasis on the social dimension of FLE, Dewaele and MacIntyre (2016) reported that an appropriate atmosphere as well as a supportive teacher and encouraging peers can set the stage for learners' sense of satisfaction and; thus, feeling of enjoyment. On the other hand, using an ecological framework of analysis, recent research (e.g. Gkonou 2017; Kasbi \& 
Elahi Shirvan, 2017; Saghafi, Adel, \& Zareian, 2017) has stressed the contribution of nested contextual agents to the emergence of language anxiety patterns.

In addition, dynamic systems self-organize into preferred states known as attractor states (Larsen-Freeman, 2006). For example, the presence of teachers' feedback as an attractor can lead the anxiety system to a low-anxiety state whereas its lack can shift the system into a high-anxiety state (Elahi Shirvan \& Talebzadeh, 2017). Also, some topics like talking about hobbies or describing a family member can attract learners' communication enjoyment to a high enjoyment state (Elahi Shirvan \& Talebzadeh, 2018 a). It is this self-organizing capacity of the dynamic systems of enjoyment and anxiety in learning a foreign language which necessitates further investigation into the construction of attractor states of these emotions. Despite the research in this realm, the developmental paths leading to these states have not been investigated yet. This is not possible unless we take advantage of appropriate methodologies like RQM.

\subsection{Retrodictive Qualitative Modeling}

Since the 'dynamic turn' in the field of applied linguistics, scholars have "found themselves not only without any templates or traditions they could rely on in producing workable and productive research designs, but also without a coherent set of new research metaphors to use" (Dörnyei, MacIntyre, \& Henry, 2015, p. 10). However, researchers have recently been developing various methodological frameworks for investigating studies from dynamic system perspective such as the idiodynamic method (Gregersen, MacIntyre, \& Olsen, 2017; MacIntyre, \& Legatto, 2011) and motometer (MacIntyre, Gregersen, \& Meza, 2014). Among them, one of the novel approaches, shifting away from the traditional attention on prediction to a "retro-diction" point of view (Chan et al., 2015, p. 3), is RQM (Dörnyei, 2014; Dörnyei \& Ryan, 2015) in which, in contrast to traditional approaches, the end-states are identified initially and, by working backwards, the developmental routes leading to outcomes, or attractor states, are revealed (Chan et al., 2015; Dörnyei, 2014).

Since complex systems are emerging, unpredictable, open, and adaptive (LarsenFreeman, 2016; Van Lier, 2004), patterns of behavior are likely to emerge in different situations (Chan et al., 2015). Therefore, the outcomes of these systems settle down in states known as attractor states (Hiver, 2015). Attractor states are in fact the result of self-organization where the systems self-organize into more preferable states (Hiver, 2015; Juarrero, 1999). The aim of using RQM is to follow back the changes and patterns leading to the main attractor states or underlying patterns, known as signature dynamics (Dörnyei, 2014; Hiver, 2015; Kelso, 2002), to observe the initial causes of certain affect archetypes found in learners. Thus, RQM supports understanding self-organization as well as exploring the signature dynamics in complex systems, providing a researchable survey of dynamic behaviors in these systems. 
Regarding the application of RQM, it has been recently used by Chan et al. (2015) and Hiver (2017). Chan et al. (2015) took advantage of RQM to follow back the signature dynamics of learners' second language motivation. They came up with seven archetypes, considering the learners' motivation as well as their language proficiency, and discussed an in depth analysis of each archetype with the signature dynamics leading to them. In addition, Hiver (2017) applied RQM to explore signature dynamics of language teacher immunity and described the developmental traces of trajectories leading to the teachers' motivated thoughts. The use of RQM in these two pioneer studies in the field of applied linguistics paves the way for the application of this innovative method in issues which have been recently addressed from a dynamic perspective such as the investigation of trajectories of positive and negative emotions in learning English as a foreign language (EFL). The dynamics of both positive and negative emotions, in particular change in enjoyment and anxiety, have been highlighted in recent research (e.g. Deweale, \& Deweale, 2017; Deweale, \& MacIntyre, 2014, 2016; Deweale et al., 2017; Elahi Shirvan \& Talebzadeh, 2017; MacIntyre et al., 2014; Gregersen et al., 2017). Yet no study has been designed to view anxiety and enjoyment as archetypes and trace their route and signature dynamics, using an RQM method. Thus, the purpose of this study is to provide a clear understanding of self-organizing patterns of FLE and FLCA alongside their signature dynamics in EFL learners.

\subsection{Research questions}

1. What are the typical emerging archetypes of EFL learners' FLE and FLCA?

2. What are the developmental processes generating EFL learners' FLE and FLCA?

\section{Methodology}

\subsection{Participants}

Following Chan et al. (2015), the participants of this study were selected in two phases. In the first phase, eight teachers (five male, three female), teaching English in one of the institutes of Mashhad, Iran, for seven years, were invited to take part in a focus group interview. In the second phase, in order to identify signature dynamics of enjoyment and anxiety, eight to fifteen students for each distinguished archetype were selected. They were all students learning English in the same institute that the participating teachers worked. Their proficiency level ranged from pre-intermediate to upper-intermediate. Their age ranged from 18 to 20 and their first language was Persian. By the time of learning English at the institute, they had already learned English at Iranian public schools for six years. At the institute, they learned English based on the principles of communicative language teaching. The teachers were present in the second phase of the process picking the best candidates to fit into the archetypes based on their observations and teaching repertoire.

\subsection{Data collection}


Dörnyei (2014) suggested a qualitative approach for the operationalization of RQM. Identifying salient learner types or attractor states in the classroom was the first step. Inspired by Chan et al. (2015), we applied a social categorization process involving a teacher focus group. That is, social categories were created by "putting some people into one group based on certain characteristics and others into another group based on their different characteristics" (Aronson, Wilson, \& Akert, 2013, p. 379). Teachers mainly make these categories based on the stored information in their long-term memory (Macrae \& Bodenhausen, 2000). Thus, as suggested by Dörnyei (2007), we carried out interviews with the teachers to provide us with their personal views about their students' levels of enjoyment and anxiety. We guided them to think about the qualifications and the adjectives (Chan et al., 2015) their students might have that place them in a certain category. That is, we asked the teachers to brainstorm student types based on their levels of enjoyment and anxiety (e.g. enjoyment + anxiety + ) and to provide us with some specific features of these types such as their level of engagement in classroom activities, preparation for the classroom tasks and activities, willingness to express themselves, to name a few. Reaching a full agreement among all the teachers in the focus interview might be farfetched, but due to the familiarity of the teachers in the focus group with their students in the institute, the argument for selecting archetypes until reaching a saturation level among almost all the eight teachers seemed sound. Considering the limitations of using RQM, since nominated prototypical learners might not be always willing to be interviewed (Chan et al., 2017), we asked the teachers to nominate the learners resembling the prototypical learners as well.

Second, after the archetypes were established based on the critical case sampling (Dörnyei, 2007), the teachers selected students that best fit the archetypes during the second round of interviews. We asked them to nominate candidates among their students for each archetype. We gave them the list of their students' names in their classes at the time of data collection and asked them to nominate the students best representing each archetype and also those resembling the prototypical learner for each archetype (regarding as reserves if the best nominee could not for any reason attend the interview session). The teachers talked about the possible candidates and checked the suitability of their choices. They agreed on 8 to 15 learners for each archetype, with 4 to 6 learners as prototypical learners or best fitting each archetype.

Third, having selected our sample of students for each archetype by the teachers, we invited the candidates to a semi-structured interview to confirm their categorization in the archetypes (see appendix A). Furthermore, we asked them to fill out the foreign language enjoyment scale (Deweale, \& MacIntyre, 2014) and foreign language classroom anxiety scale (Horwitz, Horwitz, \& Cope, 1986) until satisfaction with the selected students in terms of their archetype was achieved.

After establishing the archetypes and selecting the best fit students for each archetype based on their scores of enjoyment and anxiety scale as well as the teachers' judgment for each archetype, they were invited to an interview in order to trace back the causes of their enjoyment and anxiety throughout their experiences of 
learning English language. For this purpose, we conducted a semi-structured interview to provide data on the participants' experiences (see appendix B). We should note that since all the nominated prototypical learners agreed to be interviewed, we did not invite those who resembled the prototype learners for the interview. The prototypical learners were mainly asked about their personal experiences and causes of their emotional changes as well as different internal and external factors influencing their emotions such as their family, teachers, and classroom environment. Inspired by Chan et al. (2015), we also asked the participants to sketch a diagram of their enjoyment and anxiety experiences throughout the years they had spent on learning English language. In order to achieve "a thicker description of the attractor states" (Chan et al., 2015, p. 20), apart from the interviews and the self-sketched diagrams, we provided the participants with narrative frames (Barkhuizen \& Wette, 2008). Narratives as stories and personal experiences (Connelly \& Clandinin, 1990; Pavlenko, 2002) were found useful in this study since they contain "recursive chain of events" (Labov, 2006, p. 39). The narrative frames took into account three dimensions of time, space, or the physical setting as well as the participants' experience and interaction with others. Since these frames involve the dimensions leading to "unified episodes" (Polkinghorne, 1995), or attractor states in our study, they seemed suitable for the collection of the data for RQM.

\subsection{Data analysis}

The data provided from the interviews were transcribed via MAXQDA software (Belous, 2012). The transcriptions were translated into English and were read several times by both researchers of this study. Key words were identified, important points were highlighted, and ideas were generated. Conducting a content analysis, we explored the factors like personal, social, or contextual ones contributing to the participants' FLE and FLCA in different stages of their academic lives. These factors and their interactions were coded into different categories. To come up with wellorganized patterns, following Gibson and Brown (2009), we examined the common and different points across participants. Applying an interpretive approach, in the analysis the focal participants' transcripts, we used complex dynamics systems theory (Larsen-Freeman \& Cameron, 2008) as the foundation for reasoning the factors leading to emotional changes and discovering themes or attractor states which attributed to these changes. The narratives were carefully read and the factors influencing certain outcomes of enjoyment and anxiety were highlighted (i.e., teachers' role). Brief data from the interviews and the narratives of one best fit candidate for each archetype are presented in the results.

\section{Results}

\subsection{The archetypes of FLE and FLCA}

The teachers' focus group provided a category of four possible archetypes including anxiety and enjoyment. The archetypes are as follows: 


\section{High enjoyment and high anxiety}

According to the teachers, these students are extremely active in classroom tasks and put a lot of effort in different processes of learning by making the best out of what they can do while being highly anxious to do their best and fear failure to a great extent.

\section{High enjoyment and low anxiety}

Similar to the first archetype, these students enjoy not only classroom activities but also their individual learning. Since they experience low levels of anxiety, they are more confident and tend to enjoy themselves more compared to the first group and use any little excuse to enjoy the process of language learning.

3. Low enjoyment and high anxiety

As the teachers explained, the students fitting in this category are more or less anxious about exams and tasks in language classes and find themselves not only dealing with high levels of anxiety in language learning but also having the least possible positive feeling towards it.

\section{Low enjoyment and low anxiety}

The final archetype encompasses those students who are only physically present in class. They hardly have enough concentration and focus on the content and process of learning. Besides, nothing seems to make them happy to enjoy the lesson.

\subsection{Identifying students for each archetype}

In the second phase, the teachers selected the students in their classes who were representing the archetypes. They were then interviewed briefly so that we could confirm their types with the developed archetypes. Among the interviewees, four students having the most similar characteristic to the archetypes, prototypical learners, were then invited to the second interview in order to move on to the third phase, that was tracing the signature dynamics of their anxiety and enjoyment. Table 1 shows the archetypes and the prototypical learners as well as quotes about them expressing their archetypes.

Table 1.Emerging learner types in enjoyment and anxiety based on interviews 


\begin{tabular}{|c|c|c|c|}
\hline Prototype (Pseudonym) & Enjoyment & Anxiety & Quotes \\
\hline $\begin{array}{l}\text { High enjoyment level and } \\
\text { high anxiety level } \\
\text { (Delsa) }\end{array}$ & $\begin{array}{l}\text { Loves learning a foreign } \\
\text { language, takes advantage } \\
\text { of different opportunities to } \\
\text { speak a different language }\end{array}$ & $\begin{array}{l}\text { Trouble with confidence } \\
\text { and lack of efficient self- } \\
\text { esteem }\end{array}$ & $\begin{array}{l}\text { I have to be the best version } \\
\text { of myself and thinking } \\
\text { about not being able to do } \\
\text { that, makes me unhappy } \\
\text { and anxious }\end{array}$ \\
\hline $\begin{array}{l}\text { High enjoyment level and } \\
\text { low anxiety level } \\
\text { (Sara) }\end{array}$ & $\begin{array}{l}\text { Loves challenge and enjoys } \\
\text { difficult tasks more }\end{array}$ & $\begin{array}{l}\text { Difficult tasks not only } \\
\text { cause no anxiety, but is a } \\
\text { motivation to try harder }\end{array}$ & $\begin{array}{l}\text { When I finish a task with } \\
\text { success, it is the best feeling } \\
\text { in the world. I want to be } \\
\text { the best }\end{array}$ \\
\hline $\begin{array}{l}\text { Low enjoyment level and } \\
\text { high anxiety level } \\
\text { (Parya) }\end{array}$ & $\begin{array}{l}\text { Doesn't like anything } \\
\text { related to English }\end{array}$ & $\begin{array}{l}\text { Not confident, dissatisfied } \\
\text { with her English } \\
\text { proficiency, high amounts } \\
\text { of anxiety }\end{array}$ & $\begin{array}{l}\text { I'm not good enough and } \\
\text { having to study something } \\
\text { I don't like just makes the } \\
\text { procedure way more } \\
\text { stressful }\end{array}$ \\
\hline $\begin{array}{l}\text { Low enjoyment level and } \\
\text { low anxiety level } \\
\text { (Mahshid) }\end{array}$ & $\begin{array}{l}\text { Doesn't enjoy learning } \\
\text { English much }\end{array}$ & $\begin{array}{l}\text { Doesn't experience anxiety } \\
\text { often }\end{array}$ & $\begin{array}{l}\text { This is just something } I \\
\text { have to do }\end{array}$ \\
\hline
\end{tabular}

\subsection{Identifying signature dynamics}

In the third and final phase of this study, the trends and trajectories of the dynamics of enjoyment and anxiety were retrodicted. For this phase, we provided the emotional signature dynamics of the best-fit prototypical learners for all the four archetypes. The results and discussion contain an overview of the four prototypical learners' journey of language learning with a focus on their enjoyable and anxiety generating experiences.

\subsubsection{Signature dynamics of high enjoyment and low anxiety (Sara's case)}

Sara, an 18-year-old university student, majoring in the field of teaching English as a foreign language, started learning English at the age of 6, with the help of her father.

Sara: My father is an English teacher. When I was 6, my brother was born and my father talked to him in English and I got familiar with this language. It actually encouraged me to try using words I had learnt from their talks whenever I talked with my father.

Interviewer: Did you enjoy it?

Sara: Well of course, I felt extremely proud of myself when I started making sentences. I looked up to him and tried to copy what he said. I wanted to be just like him, following his footsteps, and talk in English with my little brother.

Sara's main source of inspiration to learn English was her father since she was a child. She enjoyed learning from her father as a role model. She said "My father was my teacher and I only loved English when he was there."

Interviewer: Did you ever have a teacher besides your father in school?

Sara: I did. In junior high school my teacher was my dad's colleague.

Interviewer: How did that make you feel? 
Sara: I hated it. She knew who I was and knew my dad well. I always felt she expected too much of me. Sometimes I even skipped classes just to push this pressure away.

Interviewer: Did that affect your enjoyment in learning?

Sara: I only felt anxious in that class because of her familiarity with me and my family. At other times, not really, English has always been a big part of my life.

We see that Sara's basis of enjoying language learning was her father's emotional support even in critical moments in her learning process. During the years of high school, she experienced high enjoyment as she was so determined in improving her English to pursue her academic goals.

Sara: This is what I have always wanted. It's like a dream come true one day, and I aim to develop my English skills and get my Ph.D. Besides, this way, I am following my dad's footsteps.

Interviewer: Is learning English more enjoyable for you at university than in high school?

Sara: Definitely.

Interviewer: What makes it more enjoyable for you?

Sara: It's more serious now. Before university, it was only regular books in school or story books. I mainly self-studied but it wasn't anything professional. Now I feel learning English is useful, and I enjoy it more when I face more difficult tasks.

Interviewer: Interesting. Don't difficult tasks make you anxious?

Sara: Actually they get me more motivated when I complete them; it's a nice feeling coming over me after doing them.

Although Sara seems to be a learner with rather low levels of anxiety, she does mention that at times she feels she is not good enough which renders her rather anxious but she easily overcomes it by involving herself in challenging tasks. She said: “sometimes when I don't understand a task, I get anxious and sometimes I question the level or the nature of the task, but once I start making sense of what needs to be done to do it well, I feel powerful again and I just know I can do it right".

Based on the interview with Sara, we see that she has mostly been enjoying learning English throughout her life with only experiencing anxiety at junior high school mainly due to her teacher as the main source of anxiety.

Interviewer: Now in university classes, you have different professors. How does that make you feel?

Sara: Well now I am more confident. Even though I still prefer to have my father as a teacher, I am not feeling anxious because all teachers now seem supportive despite having their own teaching philosophy.

Sara, a high enjoyment and low anxiety archetype representative makes it clear how her enjoyment has emerged and stabilized over the years. Starting from the beginning of her language learning journey, Figure 1 shows Sara's trajectories during 13 years since she started school until her entrance to university. 


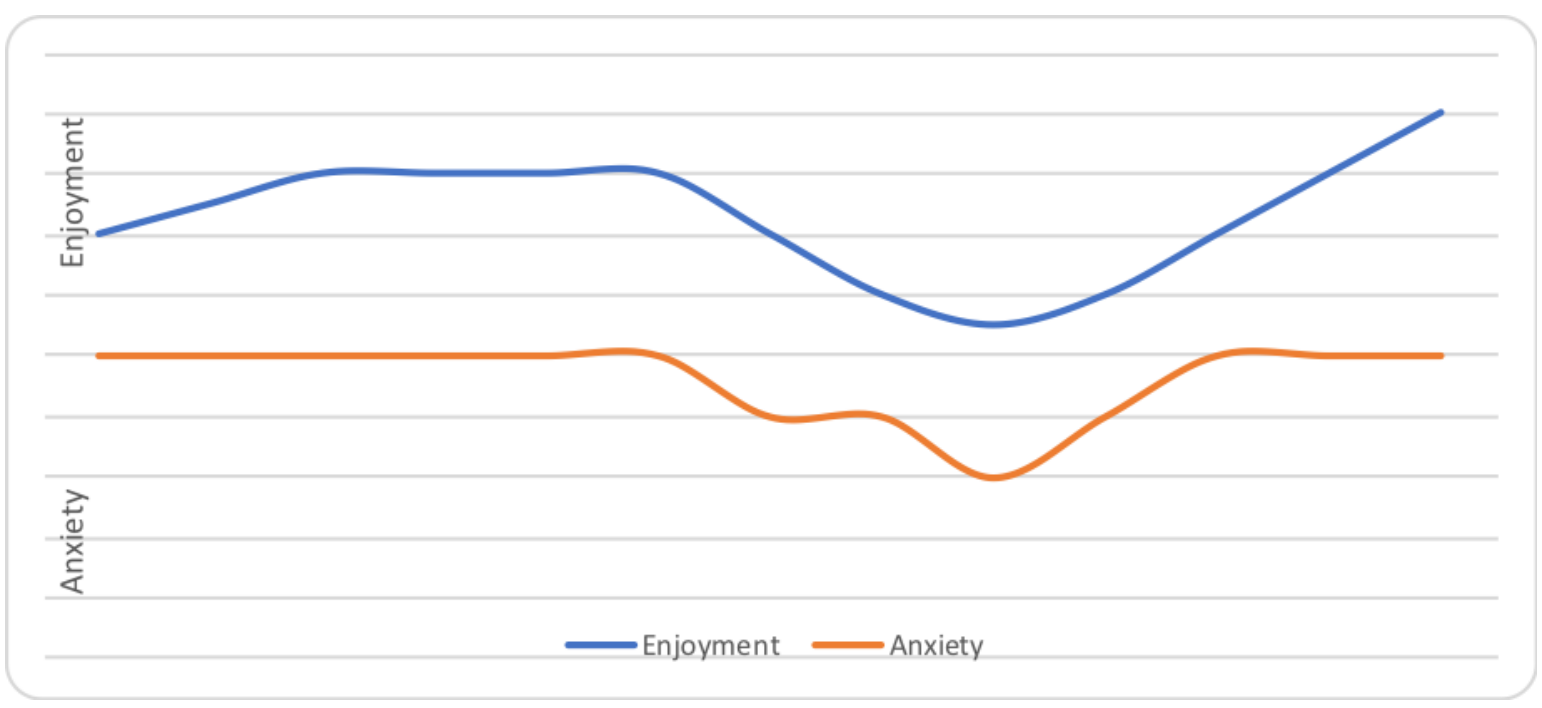

Figure 1. Sara's dynamic trends of anxiety and enjoyment

We see how Sara's level of enjoyment and anxiety has changed throughout the years of studying English. Each time a change occurs, it is due to a different reason. Her high enjoyment level in the first few years was due to her father's support and her excitement in the ability to create sentences in a different language. By the 10 th year, the reason of her high enjoyment level was her aim in succeeding in the university entrance exam to continue learning English more academically. And eventually in the final year, the most enjoyable experience she has had, her success in learning English academically, is a significant emergent pattern in her dynamic emotional experience.

The retrodictive power of these attractor states in Sara's emotional system can be better explained in terms of learners' personal styles. Personal styles (Stewart \& Joines, 1987), are an ego-state which describes how one thinks; for instance, one might behave similar to a parent, absorbed in the years spent with them (similar-to-aparent), relies on the thoughts and behaviors one remembers as a child (similar-to-achild), or depends on the thoughts of here and now rather than previous experiences (similar-to-an-adult). We can see how in Sara's case, her personal styles have changed throughout the years in relation with her teachers. In the first years of her language learning, she tried to learn from her father, placing him as a role model by copying what he did in her interactions with her younger brother. As she grew up and went to junior high school, her personal style shifted from similar-to-a-parent to similar-to-achild. As she described in the interviews, the experience of learning English with her father's support was so extraordinary for her that she could not stand accepting another one as her language teacher. Stating that she only enjoyed learning when her father was her teacher confirms her attachment to childhood feelings and behaviors and the desire to remain in that zone emotionally. Another shift in her personal style was also observed after the eleventh year when she could finally reach equilibrium in her personal emotions and her current state acquiring a similar-to-an-adult. Tracing back the shifts of her personal styles, we conclude that each style contributed to its 
own unique emotional attractor state as in her state of similar-to-a-child, in which enjoyment was less, turning this style into an attractor state of lower levels of enjoyment for Sara. In addition, similar-to-an-adult style supplements another scenario for a high enjoyment level attractor state.

\subsubsection{Signature dynamics of high enjoyment and high anxiety (Delsa's case)}

Delsa, was categorized into high enjoyment and high anxiety archetype since, according to her interviews, she enjoys learning a foreign language, whether English or any other language, but since she strives to be the best, she is highly anxious. In her narrative frame she noted:

Ever since I was a teenager, I fell in love with learning another language. Not only English, any language. I started working on my speaking because it felt great to be able to speak right in a different language but I could never speak in public. I get anxious when the teachers ask me questions and I forget how to talk. I talk with one of my friends in English all the time, but in public situations I lose my confidence. Besides my love for a foreign language, I love to teach. I love to teach English and this makes me try even harder, to at least overcome my fears. When I see a peer more proficient than myself, I feel highly anxious and because I want to be the best at what I do, my anxiety increases. I have to be the best version of myself and thinking about not being able to do that makes me unhappy and anxious. Sometimes I think, teachers seeing this passion of me for learning English, expect me to do my best all the time. So, feeling sometimes highly anxious to meet their expectation, I feel highly engaged and going though high moments of enjoyment keeping the image of their satisfaction in my mind.

Reports of her interviews and narratives indicated that her anxiety is rooted in her desire to be better than others especially in exams and classroom activities. Therefore, retrodicting a major factor contributing to the rise of anxiety in a high enjoyment-high anxiety prototypical learner, as in Delsa's case, seems to be, despite her strong engagement in the activities, her competitive spirit intertwined with a perfectionist attitude. Delsa's passion in learning English is accompanied with her desire to be the best learner in the class; thus, accomplishing this and fulfilling the expectations of the teachers have rendered her anxious during her history of English language learning but her intention to show herself qualified and proficient to receive her teachers' satisfactory confirmation has located her in the high enjoyment attractor state. Delsa's emotional experiences of anxiety and enjoyment in her narrative are reverberated in her diagram of emotional trajectories (see Figure 2).

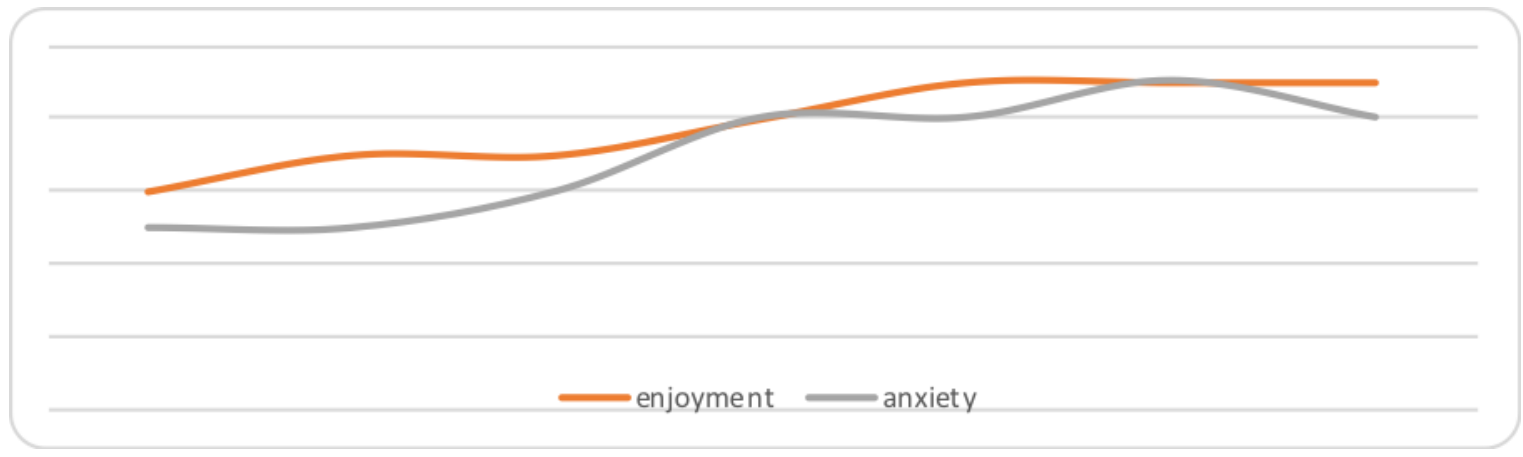


Figure 2. Delsa's dynamic trends of anxiety and enjoyment

\subsubsection{Signature dynamics of Low enjoyment and high anxiety archetype (Parya's case)}

Parya, the learner representing low enjoyment and high anxiety archetype, mentions there is nothing about language learning in which she enjoys and she always feels pressured and overwhelmed when exposed to difficult and even easy tasks. In her narrative frame she reported:

At both junior and senior high schools, English was never taken seriously. It was only a mandatory course to learn lists of words and conversations just to use in the university entrance exam. It was a course like any other courses; I studied it like them. Honestly, I hate it when the teachers talk in English. Sometimes, as I mainly experienced on high schooldays, they kept talking so fast without caring how anxious we got. They seemed so proud of themselves The only place I feel good about English is where we do group works because my friends are there to help me out, but even in those cases even if the assignment is easy I can't stand being a part of it because some group members see themselves superior to us. Doing the assignments is so tough, especially when we are reminded of the exam day and that the assigned tasks make us prepared for the final day. This is something which I have always experienced almost always in my education. It seems that we should be always ready for a final day. Even when we have to study for an exam, it is the worst nights because I know I'm not good enough and having to study something I don't like just makes the procedure way more stressful.

Retrodicting the attractors of high anxiety-low enjoyment prototype, as in Parya's case, we can refer to the washback effect of exams. Delsa has lost the here-and-now sense of enjoyment in the class due to the dominant shadow of there-and-then. As a result, she has mainly settled in a state of high anxiety where vibes of enjoyment could hardly emerge. Another factor strengthening this state for Parya is her classmates' sense of superiority, developed in the dominant competitive atmosphere of the class, which weakens any possible active enjoyment senses. Figure 3 illustrates Parya's emotional trajectories during her English language learning lifetime. As seen in Figure 3, there is a match between her emotional trajectories of enjoyment and anxiety, and her narrative of these emotional experiences in her lifetime of English as foreign language learning.

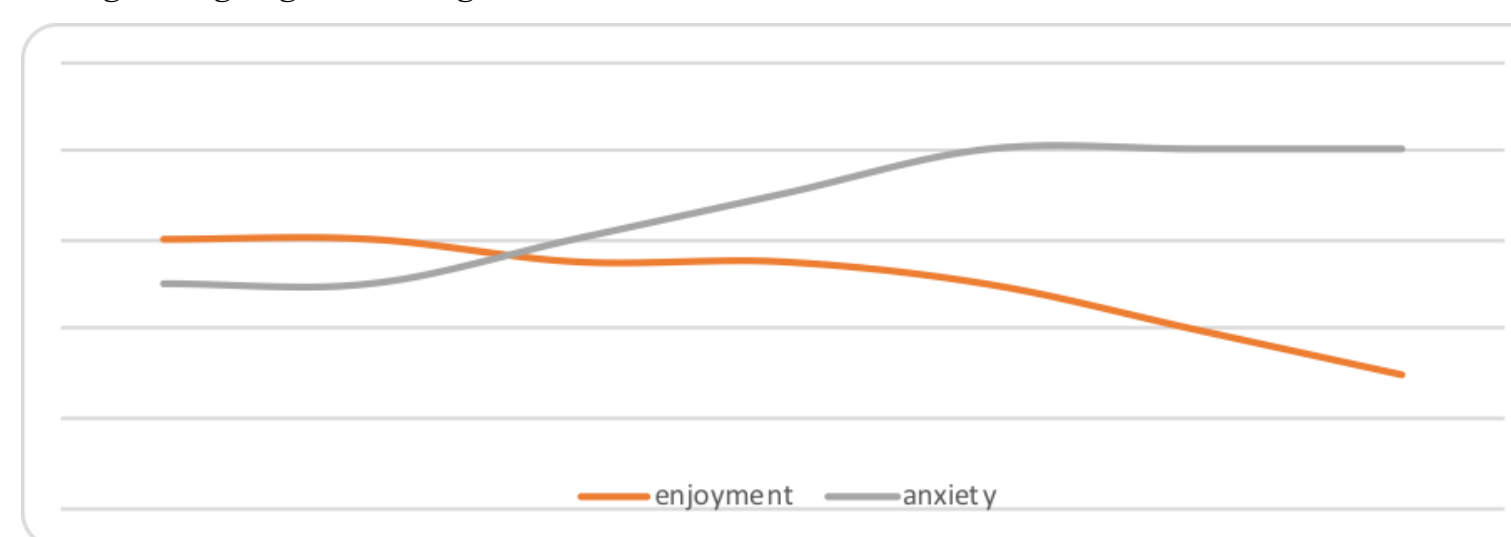


Figure 3. Pariya's dynamic trends of anxiety and enjoyment

\subsubsection{Low enjoyment and low anxiety archetype (Mahshid's case)}

The best fit for the final archetype, low enjoyment and low anxiety, was Mahshid, a nonchalant learner of English, learning English only because she finds it a responsibility and in her own words "something that has to be done". In her narrative frame she wrote:

The time I studied English the most was in high school and it was only to get into medical field of study at university. I did not enjoy it nor made me anxious cos I just aimed to pass the university exam section of English language so that I could acquire a good rank to study in the field of medicine. At high school, I was not really into the classroom activities and did not pay much attention to the teachers' comments. I was only focused on the supplementary books preparing me for the English section of the entrance exam for four years I studied at home myself. But I didn't succeed in the exam; I mean I do not study medicine now but I still continue learning English because they say it is important. I come to class and yeah....it's fine, but it's just something I have to do. Learning English has always been a must to me. I needed it to reach the goal I had before, and now that I don't have that, it's really not important. Sometimes I feel anxious about the exams but I don't let myself feel that way for long (laughs). When I get a good or bad grade, it doesn't influence me emotionally. As I said, it's just a path and it's something I have to do. I have talked to some of my teachers, but seeing me disappointed, having listened to me for a while, they get tired.

As clear in her narrative frames, this learner experiences little to no enjoyment and anxiety and she feels this in her other courses as well. Thus, retrodicting the factors influencing the low enjoyment-low anxiety archetype, as in Mahshid's case, we can explain that the routinization of previous experiences can direct learners to an attractor state in which they might experience a sense of indifference in terms of both enjoyment and anxiety. Mahshid's history of emotional experiences in her narrative frames is in line with her self-sketched diagram of emotional trajectories (see Figure $4)$.

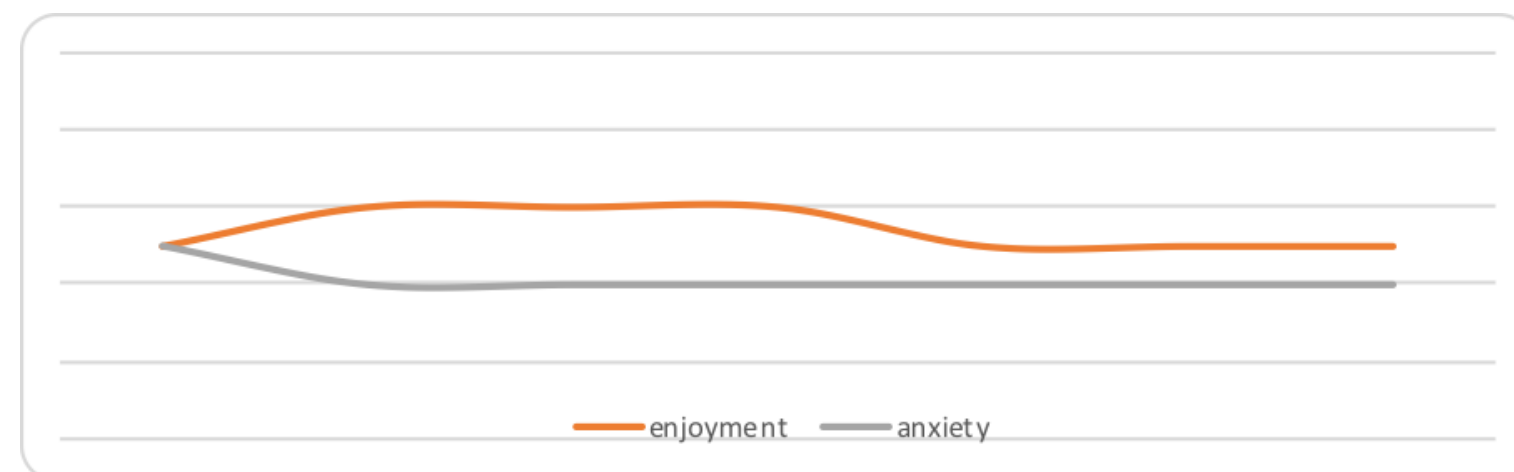


Figure 4. Mahshid's dynamic trends of anxiety and enjoyment

\subsection{The retrodictive role of English language teachers in the emotional trajectories of the prototypical learners}

A major attractor observed in this study was the role of the prototypical learners' teachers in constructing their archetypes of enjoyment and anxiety. This retrodictive role of teachers can be explained in light of their life position. From the perspective of teachers' life position based on transactional analysis theory (Bern, 2016), in a classroom where the teacher's life position is I'm ok, you're ok, similar to Sara's conditions, enjoyment can be in its peak with few to no moments of anxiety. Where this life position is I'm ok, you're not ok, such as Parya's emotional experiences during high school, teachers' anxiety provoking presence and behavior might not be bridged with any enjoyment building devices; thus, low enjoyment binds with high anxiety. In a setting where the teacher's life position is I'm not ok, you're not ok, as might be in Mahshid's case; teachers may lose their powerful contribution as a source of learners' emotion; therefore, learners might settle in a state where neither enjoyment nor anxiety emerges.

\section{Discussion}

A complex system involves emerging and unpredictable patterns, but even considering this, the RQM method suggests that these systems self-organize into limited and more preferable states known as attractor states. The findings of this study confirmed the assumption that due to their self-organizing capacity, complex systems show a limited number of patterns. The participants' emotional system was attracted to some specific space states arousing anxiety, enjoyment, both, or neither of these emotions.

Furthermore, in line with the "the existence of settled attractor states" in dynamic systems (Chan et al., 2015), the findings showed that archetypes regarding enjoyment and anxiety in foreign language exist in teachers' mind. That is, the teachers perceived enjoyment and anxiety in their learners in terms of a small number of patterns. This justifies the theory of social categorization underpinning the RQM based on which teachers and practitioners are believed to be aware of familiar types of learners based on their intuition. However, it should be pointed that some cases of mismatch between the teachers' selection of prototypical learners and the description of archetypes were observed. This might be rooted in the illusion of transparency in enjoyment (Elahi Shirvan \& Talebzadeh, 2018 b) and anxiety (Gregersen, MacIntyre, $\&$ Olsen, 2017) in which verbal and nonverbal cues of both emotions are not fully perceived by the teachers due to their situated nature. Another similar reason for this can be explained in terms of "actor-observer effect" (Chan et al., 2015, p.18) in which "attributions differ as a function of the perspective of the attributor" (Robins et al., 1996, p.375). Since teachers have different sources of information or different 
attention to even the same sources of information, they come up with different attributions regarding their learners' enjoyment and anxiety.

Regarding the identification of the initial conditions (MacIntyre \& Gregersen, 2012) in terms of the attractor states the emotional system occupies, we can consider Sara's interest in her father, as a role model, as initial conditions when she starts learning English. The extent to which the participants' initial conditions influence the system's future development depends on whether it is in an attractor state or not (Lowie \& Verspoor, 2015). It is postulated that if the system is initially "lodged in a deep-sided attractor basin", initial conditions can strongly influence the subsequent developments. For Sara, her enjoyment in learning English is the result of her enthusiasm in her father as well as his acknowledgement of her learning English language. In contrast to Elahi Shirvan and Taherian (2018) reporting no association between learners' initial state and their growth in FLE and FLCA and despite the fluctuations in the path of emotional system across the state space, the initial emotional conditions in this study continued to have an enduring influence on the growth of the system in that the system is inclined to "gravitate back to the powerful attractor state" like emotional support of Sara's father or to the initial interest in learning languages as in Delsa's case.

This discrepancy, observed between the findings of Elahi Shirvan and Taherian (2018) and those of the present study, might be explained in terms of the period of time the system is investigated. Elahi Shirvan and Taherian (2018) studied change in a period of four sessions, but RQM addresses a broad range of time by taking different stages of individuals' life time.

Talking about the underpinning dynamic mechanisms in emotional systems, patterns of emotions emerge as the system moves between a set of attractor states. In Sara's case, the system goes through a change when she enters junior high school. In this stage of her life, she experiences moments of feeling anxious. She does not mention the context of the class and the materials for learning English as the sources of her anxiety. Nor does she refer to the tasks and classroom activities in the class as anxiety generating factors. Rather, it is the teacher in the class who directs the system into a new attract state in which she is to live up to her teacher's expectation due to her familiarity with her father. She feels under pressure that she might lose her self-esteem if her performance in the class does not seem satisfactory to this teacher. But it is interesting that due to this familiarity, the system regularly moves into and out of this zone of its state space shaping two pivotal tendencies, approaching enjoyment and avoiding anxiety which is in accordance with the operational definition of periodical shifts between attractor states (Larsen-Freeman \& Cameron, 2008; Hiver, 2015). In other words, the enduring effect of emotional support on the part of Sara's father and the fear of self-esteem loss in the class function as twin cyclical attractors between which the system shifts.

In case of Delsa, her interest in learning languages shifts to new space states in the system; that is, meeting the expectations of her teachers and the competition force 
both contribute to the emergence of enjoyment and anxiety in the system. This is consistent with Dewaele and MacIntyre (2014, p. 3) contending that enjoyment and anxiety "are not the opposites of the same experience" because these emerging attractor states in Delsa's lifetime generate both emotions.

For Parya, the emotional system initially moves between the two attractor states of fear of failure in exams and the competition force as both induce anxiety in the system. The summative assessment dominant in her English classes as well as the peer pressure existing in her group work experiences made the system move in a close periodical loop of anxiety generation. However, lack of emotional support within the context of the classroom from the teachers, as a third attractor, attracts the system to itself which contribute to cyclical shifts between the three attractors introducing Parya as a high anxiety-low enjoyment prototypical learner.

For Mahshid, the system shifts between two emerging attractors of learning English for only following academic goals and learning English for no reason (as she has not achieved the goal) both arousing neither enjoyment nor anxiety. The university entrance exam seems to be a turning point in the construction of this closed loop of low emotion attractors. It is interesting that the attractor state of pursuing academic goal does not generate high levels of emotions in her as this can be rooted in the wash-back effect of the university entrance exam in Iran in which students do not take their courses and classroom activities serious but they just focus on the books or supplementary materials preparing them for the English section of the entrance exam.

It is worth pointing that the new attractor states in the system sometimes resemble the previous ones like Sara's father's emotional support and encouragement or Delsa's image of being an English teacher. Thus, the system "reverts back" to this already detected attractor state. This is clear as Sara still emphasizes her father's role and her heavy emotional support at her college days as her main source of enjoyment in learning English, as Delsa stresses her desire to be an English teacher as her major source of interest in English, or as Parya, still associates English with primary source of anxiety which is the nightmare of the final exams. But a more noticeable example of this reverting back to the previous states can be Mahshid's emotional system. Her low generation of emotions in her college years due to her not achieving the goal of studying in medicine can be strengthened by the shift of the system to the previous state based on which the current state of hers has been built; that is, learning English only for one goal.

Thus, as the findings of this study showed, the signature dynamics can be defined as the shift of the system among several cyclic attractors. These inter-attractor cyclic shifts shaping between-states periodic movement (Larsen-Freeman \& Cameron, 2008) represent two basic emotional drives of positive and negative emotions, enjoyment and anxiety in particular, underlying the dynamics of the emotional systems. This is in agreement with MacIntyre and Serroul (2015) reporting that approaching 
situations which generate positive emotions and avoiding those that induce negative ones are two fundamental human orientations.

\section{Conclusion}

The RQM method used in this study shows to a great extent the visibility of its usage in qualitative research of the dynamics of foreign language learning variables. The purpose of this study was to move backwards to survey the causes of certain emotional outcomes in foreign language learners. The archetypes of enjoyment and anxiety might stem from attractors including the influence of the teacher, personal goals, a perfectionist image of oneself and dissatisfactory and unsuccessful experiences in the past. Awareness of these prototype contributors of emotions can help learners make meaning of how they feel at the moment in terms of their salient features of enjoyment and anxiety. It might even help them think of ways to possibly alter their emotions and enter a new, favorable, archetype. In addition, realizing the importance of teachers' role as one of the main retrodictive attractors in the construction of learners' archetypes of FLE and FLCA can give us insights to acknowledge ourselves as teachers of a foreign language, playing a pivotal role in creating these trends ourselves to make learning more enjoyable for learners and cause the least anxiety provoking environment for them.

Understanding signature dynamics of learner archetypes concerning enjoyment and anxiety in terms of the revealed archetypes in this study might contribute to deeper insights regarding the developmental routes of these emotions; however, expanding this understanding in terms of uncountable levels of enjoyment and anxiety in each individual might be also possible. For example, instead of a general categorization of high enjoyment and low anxiety level archetypes, we can question how high is high enjoyment? Are high and low enjoyment similarly defined in different learners? With this issue in mind, and consistent with Chan et al. (2015), we contend that it is only logical to categorize learner archetypes according to the most well-known, wellestablished, and obvious types. Since levels of emotions are different in different individuals, we suggest that future research can develop studies in which researchers should consider other levels of enjoyment and anxiety into account (extremely high anxiety or enjoyment, a moderate amount, no enjoyment or anxiety at all) in the construction of archetypes. In addition, the patterns leading to these archetypes are dynamic; therefore, more cases with the same archetype can be compared to one another to trace their trends and dynamic signatures, their similarities and differences, and also a response to whether these archetypes emerge from similar dynamic patterns or not. Furthermore, interviewing the people involved in the construction of the prototypical EFL students for each archetype like their teachers and family members, if possible, can provide richer documents with regard to the emerging patterns underlying the archetypes of enjoyment and anxiety. Finally, a replication of this study can lead to garnering further insights into the signature dynamics of both FLE and FLCA. 


\section{References}

Arnold, J., \& Brown, H. D. (1999). A map of the terrain. In J. Arnold (Ed.), Affect in language learning (pp. 1-24). Cambridge: Cambridge University Press.

Barkhuizen, G., \& Wette, R. (2008). Narrative frames for investigating the experiences of language teachers. System, 36(3), 372-387.

Belous, I. (2012). MaxQDA 11 [Computer software]. Marburg, Germany: Verbi Software. Retrieved from http://www.maxqda.com/

Byrne, D. (2010). Comparison, diversity and complexity. In P. Cilliers \& R. Preiser (Eds.), Complexity, difference and identity (pp. 61-75). Dordrecht, the Netherlands: Springer.

Chan, L., Dörnyei, Z., \& Henry, A. (2015). Learner archetypes and signature dynamics in the language classroom: A retrodictive qualitative modelling approach to studying L2 motivation. In Dörnyei, Z., Henry, A., \& MacIntyre, P. D. (Eds.). Motivational dynamics in language learning (pp. 238-259). Multilingual Matters.

Connelly, F. M., \& Clandinin, D. J. (1990). Stories of experience and narrative inquiry. Educational Researcher, 19(5), 2-14.

de Bot, K., Lowie, W., \& Verspoor, M. (2007). A dynamic systems theory to second language acquisition. Bilingualism: Language and Cognition, 10(1), 7-21.

Dewaele, J. M., \& Alfawzan, M. (2018). Does the effect of enjoyment outweigh that of anxiety in foreign language performance?. Studies in Second Language Learning and Teaching, $8(1), 21-45$.

Dewaele, J. M., \& MacIntyre, P. D. (2016). Foreign language enjoyment and foreign language classroom anxiety: The right and left feet of the language learner. In T. Gregersen, P. D, MacIntyre, \& S. Mercer (Eds.), Positive psychology in SLA (pp 215-236). Bristol: Multilingual Matters.

Dewaele, J. M., \&Dewaele, L. (2017). The dynamic interactions in foreign language classroom anxiety and foreign language enjoyment of pupils aged 12 to 18. A pseudo-longitudinal investigation. Journal of the European Second Language Association, 1(1), 12-22.

Dewaele, J. M., \&MacIntyre, P. D. (2014). The two faces of Janus? Anxiety and enjoyment in the foreign language classroom. Studies in Second Language Learning and Teaching, 4(2), 237-274.

Dewaele, J. M., MacIntyre, P. D., Boudreau, C., \& Dewaele, L. (2016). Do girls have all the fun? Anxiety and enjoyment in the foreign language classroom. Theory and Practice of Second Language Acquisition, 2(1), 41-63.

Dewaele, J. M., Witney, J., Saito, K., \& Dewaele, L. (2017). Foreign language enjoyment and anxiety: The effect of teacher and learner variables. Language Teaching Research, 1362168817692161.

Dewaele, J.-M. (2007). The effect of multilingualism, sociobiographical, and situational factors on communicative anxiety and foreign language anxiety of mature language learners. The International Journal of Bilingualism, 11 (4), 391-409.

Dörnyei, Z. (2007). Research methods in applied linguistics. Oxford: Oxford University Press.

Dörnyei, Z. (2014). Researching complex dynamic systems: 'Retrodictive qualitative modelling' in the language classroom. Language Teaching, 47 (1), 80-91.

Dörnyei, Z., \& Ryan, S. (2015). The psychology of the language learner revisited. London: Routledge.

Dörnyei, Z., Henry, A., \& MacIntyre, P. D. (2015). Motivational dynamics in language learning. Bristol: Multilingual Matters. 
Elahi Shirvan, M. \& Talebzadeh, N. (2017). English as a foreign language learners' anxiety and interlocutors' status and familiarity: An idiodynamic perspective. Polish Psychological Bulletin, 48(4), 489-503.

Elahi Shirvan, M., \& Taherian, T. (2018). Longitudinal examination of university students' foreign language enjoyment and foreign language classroom anxiety in the course of general English: Latent growth curve modeling. International Journal of Bilingual Education and Bilingualism, Advance online publication. doi.org/10.1080/13670050.2018.1441804

Elahi Shirvan, M., \& Talebzadeh, N. a (2018). Exploring the fluctuations of foreign language enjoyment in conversation: An idiodynamic perspective. Journal of Intercultural Communication Research, 47(1), 21-37.

Elahi Shirvan, M., \& Talezadeh, N. B. (2018). Is transparency an illusion? An idiodynamic assessment of teacher and peers' reading of nonverbal communication cues of foreign language enjoyment. Journal of Intercultural Communication Research, 47(3), 188-206.

Gibson, W. J., \& Brown, A. (2009). Working with qualitative data. London: Sage.

Gkonou, C. (2017). Towards an ecological understanding of language anxiety. In C. Gkonou, M. Daubney, \&, J. M. Dewaele, J (Eds). New insights into language anxiety: Theory, research and educational implications (pp. 136-156). Bristol: Multilingual Matters.

Gkonou, C., Daubney, M., \& Dewaele, J. M. (Eds.). (2017). New insights into language anxiety: Theory, research and educational implications. Bristol: Multilingual Matters.

Gregersen, T., Macintyre, P. D., \& Meza, M. D. (2014). The motion of emotion: Idiodynamic case studies of learners' foreign language anxiety. The Modern Language Journal, 98(2), 574-588.

Gregersen, T., MacIntyre, P. D., \& Olsen, T. (2017). Do you see what I feel? An Idiodynamic assessment of expert and peer's reading of nonverbal language anxiety cues. In C. Gkonou, M. Daubney, \& J.-M. Dewaele (Eds.), New insights into language anxiety: Theory, research and educational implications (pp. 110-134). Bristol: Multilingual Matters

Haggis, T. (2008). Knowledge must be contextual: Some possible implications of complexity and dynamic systems theories for educational research. Educational Philosophy and Theory, 40 (1), 158-176.

Hiver, P. (2015). Attractor states. Motivational dynamics in language learning. In Z. Dörnyei, A. Henry, \& P. D. MacIntyre (Eds.). Motivational dynamics in language learning (pp. 2028). Bristol: Multilingual Matters.

Hiver, P. (2017). Tracing the signature dynamics of language teacher immunity: A retrodictive qualitative modeling study. The Modern Language Journal, 101(4), 669-690.

Horwitz, E. K. (2001). Language anxiety and achievement. Annual Review of Applied Linguistics, 21(1), 112-126.

Horwitz, E. K. (2010). Foreign and second language anxiety. Language Teaching, 43(2), 154167.

Horwitz, E. K., Horwitz, M. B., \& Cope, J. (1986). Foreign language classroom anxiety. Modern Language Journal, 70(2), 125-132.

Juarrero, A. (1999). Dynamics in action: Intentional behavior as a complex system. Cambridge, MA: MIT Press.

Kasbi, S., \& Elahi Shirvan, M. (2017). Ecological understanding of foreign language speaking anxiety: emerging patterns and dynamic systems. Asian-Pacific Journal of Second and Foreign Language Education, 2(1), 2-20.

Kelso, J.A.S. (2002). Self-organizing dynamical systems. In N. Smelser \& P. Baltes (Eds) International Encyclopedia of the Social and Behavioral Sciences (pp. 13844-13850). Oxford: Elsevier. 
Krentzman, A. R. (2013). Review of the application of positive psychology to substance use, addiction, and recovery research. Psychology of Addictive Behaviors, 27(1), 151.

Labov, W. (2006). Narrative pre-construction. Narrative Inquiry, 16 (1), 37-45.

Larsen-Freeman, D. (2006). The emergence of complexity, fluency, and accuracy in the oral and written production of five Chinese learners of English. Applied linguistics, 27(4), 590619.

Larsen-Freeman, D. (2016). Classroom-oriented research from a complex systems perspective. Studies in Second Language Learning and Teaching, 6(3), 377-393.

Larsen-Freeman, D., \& Cameron, L. (2008). Complex systems and applied linguistics. Oxford: Oxford University Press.Lowie, W. M., \& Verspoor, M. H. (2019). Individual differences and the ergodicity problem. Language Learning, 69 (S1), 184-206.

Lowie, W., \& Verspoor, M. (2015). Variability and variation in second language acquisition orders: A dynamic reevaluation. Language Learning, 65(1), 63-88.

Lu, Z., \& Liu, M. (2011). Foreign language anxiety and strategy use: A study with Chinese undergraduate EFL learners. Journal of Language Teaching and Research, 2(6), 1298-1305.

MacIntyre, P. D. (1999). Language anxiety: A review of the research for language teachers. In D. J. Young (Ed.), Affect in foreign language and second language learning: A practical guide to creating a low-anxiety classroom atmosphere (pp. 24-45). Boston, MA: McGrawHill.

MacIntyre, P. D., \& Gardner, R. C. (1991). Methods and results in the study of anxiety and language learning: A review of the literature. Language Learning, 41(1), 85-117.

MacIntyre, P. D., \& Gregersen, T. (2012). Emotions that facilitate language learning: The positive-broadening power of the imagination. Studies in Second Language Learning and Teaching, 2(2), 193-213.

MacIntyre, P. D., \& Legatto, J. J. (2011). A dynamic system approach to willingness to communicate: Developing an idiodynamic method to capture rapidly changing affect. Applied Linguistics, 32(2), 149-171.

MacIntyre, P. D., \& Serroul, A. (2015). Motivation on a per-second timescale: Examining approach-avoidance motivation during 12 task performance. In Z. Dörnyei, P. D. MacIntyre, \& A. Henry (Eds.), Motivational dynamics in language learning (pp. 109-138). Bristol: Multilingual Matters.

Macrae, C. N., \& Bodenhausen, G. V. (2000). Social cognition: Thinking categorically about others. Annual review of psychology, 51(1), 93-120.

Pavlenko, A. (2002). Bilingualism and emotions. Multilingua, 21(1), 45-78.

Pavlenko, A. (2007). Autobiographical narratives as data in applied linguistics. Applied Linguistics, 28 2), 163-188.

Pluskota, A. (2014). The application of positive psychology in the practice of education. Springer Plus, 3(1), 147-154.

Polkinghorne, D.E., (1995). Narrative configuration in qualitative analysis. Qualitative Studies in Education. 8 (1), 5-23.

Robins, R.W., John, O.P., \& Caspi A. (1996) Resilient, overcontrolled, and undercontrolled boys: Three replicable personality types. Journal of Personality and Social Psychology, 7(1), $157-171$.

Saghafi, K., Adel, S. M. R., \& Zareian, G. (2017). An ecological study of foreign language writing anxiety in English as a foreign language classroom. Journal of Intercultural Communication Research, 46(5), 424-440.

Saito, Y., Horwitz, E. K., \& Garza, T. J. (1999). Foreign language reading anxiety. The Modern Language Journal, 83(2), 202-218. 
Scovel, T. (1978). The effect of affect on foreign language learning: A review of the anxiety research. Language Learning, 28(1), 129-142.

Stewart, I., \& Joines, V. (1987). TA today: A new introduction to transactional analysis. Nottingham: Lifespace Publishing

Van Lier, L. (2004). The ecology and semiotics of language learning: A sociocultural perspective. New York: Kluwer Academic Publishers.

\section{Appendix A.}

\section{Questions for the first the interviews}

1. Why did you start learning English?

2. Do you enjoy leaning another language?

3. What do you think can influence the way you feel?

4. Are you often anxious in class or relaxed?

\section{Appendix B.}

\section{In-depth questions for the second interview}

1. When did you start learning English?

2. What or who do you think motivated you from the beginning?

3. Do have an ideal image of yourself as a language learner?

4. How did the teachers affect your emotions and attitude towards language learning?

5. Do you believe your childhood has influenced your enjoyment and anxiety?

6. Do you see any difference in your emotions towards language learning in the past few years?

\section{Copyrights}

Copyright for this article is retained by the author(s), with first publication rights granted to the Journal.

This is an open-access article distributed under the terms and conditions of the Creative Commons Attribution license (CC BY-NC-ND) (http://creativecommons.org/licenses/by-nc-nd/4.0/). 